\begin{tabular}{|l|}
\hline Access this article online \\
\hline Quick Response Code: \\
\hline Website: \\
Www.jponline.org \\
\hline DOI: \\
10.4103/JLP.JLP_55_19 \\
\hline
\end{tabular}

Departments of Pathology and ${ }^{1}$ Surgery, Himalayan Institute of Medical Sciences, Swami Rama Himalayan University, Dehradun, Uttarakhand, India

Address for correspondence: Dr. Nadia Shirazi, Department of Pathology, Himalayan Institute of Medical Sciences,

Swami Rama Himalayan University, Jolly Grant,

Dehradun - 248 140, Uttarakhand, India

E-mail: shirazinadia@ gmail.com

Submission: 03-04-2019 Accepted: 01-11-2019

\title{
Von Meyenburg complex clinically presenting as metastatic liver nodule: A rare finding in an elderly male
}

\author{
Nadia Shirazi, Neena V Chauhan, Smita Chandra, Sunil Saini Kumar ${ }^{1}$
}

\section{Abstract:}

Von Meyenburg complex is a benign biliary hamartoma observed in approximately $3 \%$ of the autopsies conducted. These hamartomas are small, multiple and can be seen anywhere in the liver. There is usually no abnormality in liver function tests, and the patient is mostly asymptomatic. They serve as a diagnostic dilemma, particularly during metastatic workup in suspected cancer patients. Imaging studies are usually noncontributory, and biopsy is necessary for a definite diagnosis. We present here a middle-aged North Indian male who underwent liver biopsy to rule out metastasis.

Key words:

Bile duct, biopsy, ductal plate, hamartoma

\section{Introduction}

V on Meyenburg complex (VMC) is a benign developmental ductal plate malformation of the intrahepatic bile duct. The condition is asymptomatic and leads to hamartomatous proliferation of bile ducts anywhere along the hepatic tree. VMC has been described as early in 1918..$^{[1]}$ These hamartomas are usually smaller than $5 \mathrm{~mm}$, and hence radiological detection is seen in $<1 \%$ of cases. Its incidence based on autopsy studies is approximately $5.6 \%$ in adults and $0.9 \%$ in children. There is no particular sex predilection. ${ }^{[2]}$ The clinical differential diagnosis includes metastasis, microabscesses, simple liver cysts, etc., Even though VMC is benign and asymptomatic, the possibility of progressing to cholangiocarcinoma is a serious concern and these patients should be kept in follow-up. ${ }^{[3]}$ The case merits publication because of rarity of diagnosis and it being seen in a male in later years of life.

This is an open access journal, and articles are distributed under the terms of the Creative Commons Attribution-NonCommercial-ShareAlike 4.0 License, which allows others to remix, tweak, and build upon the work non-commercially, as long as appropriate credit is given and the new creations are licensed under the identical terms.

For reprints contact: reprints@medknow.com

\section{Case Report}

A 65-year-old North Indian male presented with yellowish discoloration of sclera, weakness, abdominal pain, and recurrent vomiting, particularly after meals for 1 month. On examination, a vague, firm-to-hard lump was felt in the right hypochondrium. His total serum bilirubin was $2.1 \mathrm{mg} / \mathrm{dl}$ (direct: $0.8 \mathrm{mg} / \mathrm{dl}$ and indirect: $1.3 \mathrm{mg} / \mathrm{dl})$. Alkaline phosphatase was almost four times elevated (367 IU/L). Albumin was low; $3 \mathrm{~g} / \mathrm{dl}$ and $\mathrm{A}: \mathrm{G}$ ratio was reversed (0.79:1). Prothrombin time and international normalized ratio were however within the normal limits. He had moderate anemia $(8.5 \mathrm{~g} / \mathrm{dl})$ macrocytic type with few target cells on peripheral blood smear. HIV, hepatitis B surface antigen, and hepatitis $C$ virus were nonreactive. Ultrasound of the abdomen showed nodular liver with occasional space-occupying lesions and few small cysts [Figure 1]. A clinical impression of neoplasia favoring metastasis was made, and ultrasound-guided fine-needle aspiration cytology was performed. The lesion was exhibiting low cellularity with a variable amount of fibrous fragments in the

How to cite this article: Shirazi N, Chauhan NV, Chandra S, Kumar SS. Von Meyenburg complex clinically presenting as metastatic liver nodule: A rare finding in an elderly male. J Lab Physicians 2019;11:385-7. 
background. A possibility of vascular lesion was rendered, and biopsy was advised. The Tru-cut liver biopsy using Menghinis needle was fragmented. There was partial effacement of lobular architecture [Figure 2]. A large number of proliferating bile ducts were seen lined by the single layer of uniform cuboidal epithelium showing no mitotic activity [Figures 3 and 4]. Mild-to-moderate fibrosis was seen around these ductules as demonstrated by special stains [Figure 5]. A diagnosis of bile duct hamartoma or VMC was rendered on histopathology. The rest of the metastatic workup were unremarkable. There were no other systemic anomalies or renal cysts, and alpha-fetoprotein levels were within the normal limits. The patient was discharged after 2 units of packed red blood cell and 2 units of fresh frozen plasma infusion. He is presently asymptomatic and is attending follow-up clinic.

\section{Discussion}

VMC or biliary microhamartomas are multiple, small $(<1.5 \mathrm{~cm})$, cystic, multinodular lesions in the

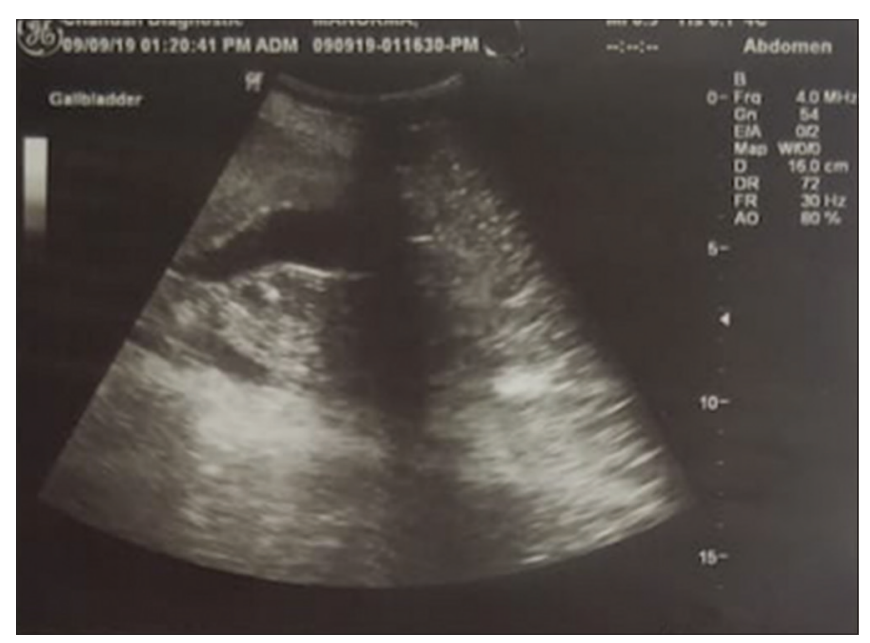

Figure 1: Ultrasound of the abdomen showing few solid, space-occupying lesions, and few cysts in the liver

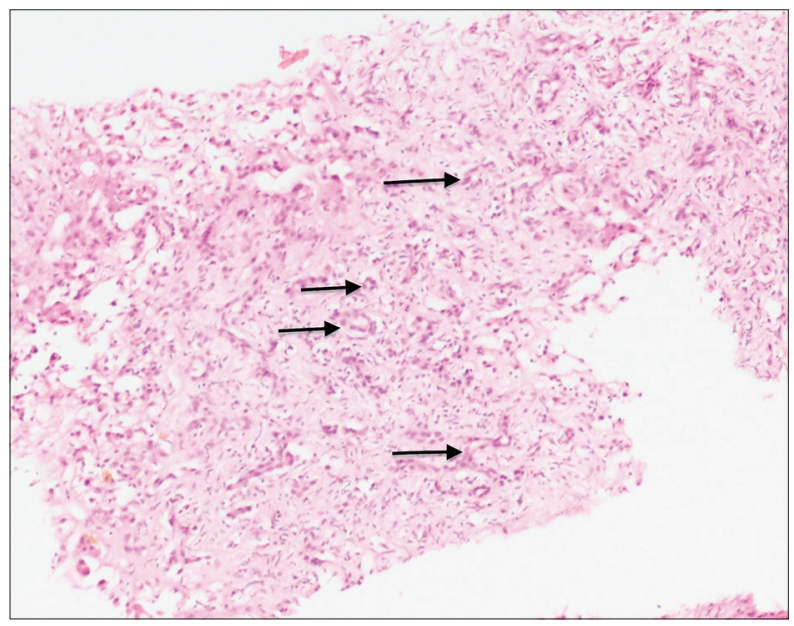

Figure 3: Proliferating benign bile ducts ( $\mathrm{H}$ and $\mathrm{E}$ stain: $\times 10 \times 10$ ) liver affecting the small intrahepatic bile ducts as a result of atypical embryonic development. ${ }^{[4]} \mathrm{VMC}$ does not usually cause altered liver function tests and is mostly asymptomatic clinically. The disease is named after a Dresden born pathologist von Meyenburg, who first described this entity in 1918. ${ }^{[1]}$ Hence, biliary hamartomas are also known as "von Meyenburg complexes." Biliary hamartomas are composed of small, haphazardly distributed aggregates of cystically dilated bile ducts lined by a single uniform layer of cuboidal cells and surrounded by fibrocollagenous stroma. They may or may not communicate with the biliary tree and are thought to arise from embryonic bile duct remnants that have failed to involute. ${ }^{[5]}$ VMC is seen to coexist with other cystic diseases such as polycystic liver disease and autosomal polycystic kidney disease. ${ }^{[6]}$ Possible malignant transformation documented is into hepatocellular carcinoma and cholangiocarcinoma. This malignant transformation has been attributed to the presence of bile (stasis) and prolonged exposure to carcinogens. ${ }^{[3]}$

Radiologically, they are seen as multiple small round or irregular lesions throughout the liver, particularly seen

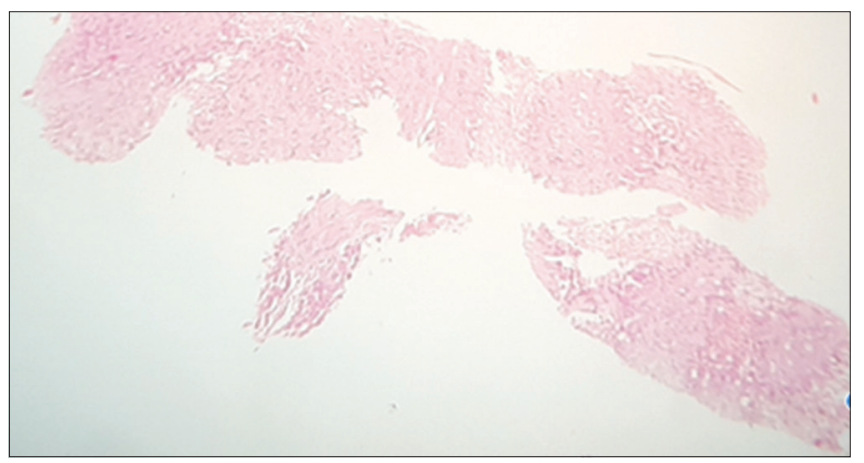

Figure 2: Ultrasonography-guided liver biopsy showing bile ducts ( $\mathrm{H}$ and $\mathrm{E}$ stain: $\times 4 \times 10$ )

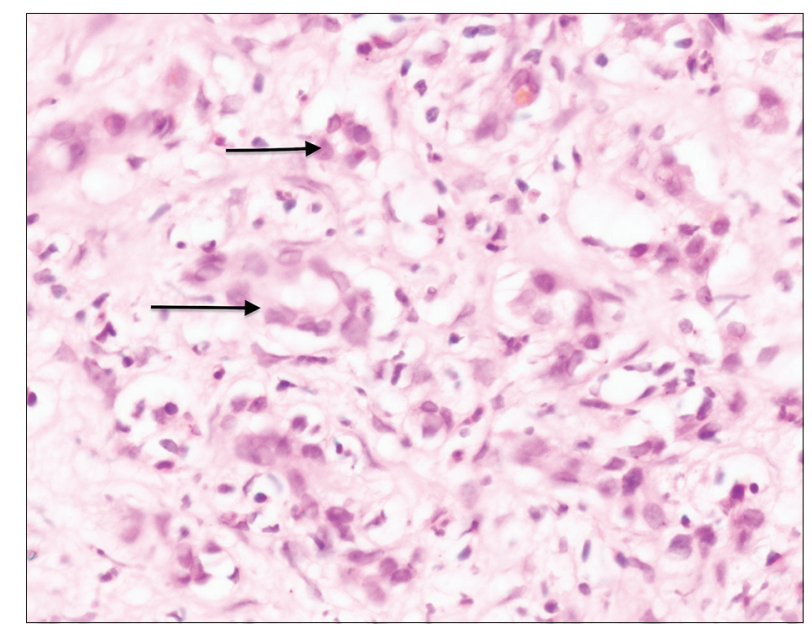

Figure 4: Ducts lined by columnar epithelium with minimal nuclear atypia ( $\mathrm{H}$ and $\mathrm{E}$ stain: $\times 40 \times 10$ ) 


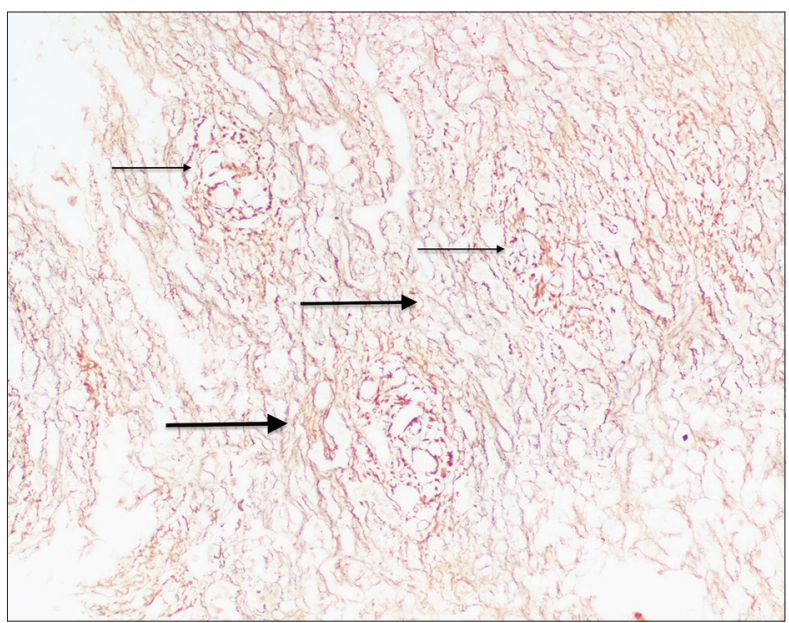

Figure 5: Increased fibrosis (thick arrow) around the benign bile ducts (thin arrow) (Reticulin stain: $\times 10 \times 10$ )

in the subcapsular region. ${ }^{[2]}$ These are usually $5-30 \mathrm{~mm}$ in size when detected radiologically; however, a lesion as small as $5 \mathrm{~mm}$ is detected on histopathology. Radiographic findings can be nonspecific and mimic metastases, parasitic and nonparasitic cysts, microabscesses, Caroli's disease, etc. ${ }^{[7]}$ Clinical presentations may range from being asymptomatic to having abdominal dissension, jaundice, recurrent infections, abdominal tenderness, fever, etc. ${ }^{[8]}$ Our patient had jaundice similar to that reported by Sinakos et al. ${ }^{\left[{ }^{[9]}\right.}$ VMC patients need to be managed symptomatically. The cysts do not require any treatment unless they are large and causing significant impairment of liver functions. The larger cysts can be managed by percutaneous drainage with sclerotherapy, surgical resection, or marsupialization. ${ }^{[10]}$

\section{Conclusion}

The possibility of VMC should be kept in mind as these lesions are rare and mimic a metastatic live nodule clinically and radiologically. The disease once detected carries a favorable prognosis with a different mode of treatment; however, these patients should be kept in follow-up as there has been evidence suggesting a strong likelihood of malignant transformation to cholangiocarcinoma or hepatocellular carcinoma.

\section{Declaration of patient consent}

The authors certify that they have obtained all appropriate patient consent forms. In the form, the patient has given his consent for his images and other clinical information to be reported in the journal. The patient understands that his names and initials will not be published, and due efforts will be made to conceal his identity, but anonymity cannot be guaranteed.

\section{Financial support and sponsorship}

Nil.

\section{Conflicts of interest}

There are no conflicts of interest.

\section{References}

1. von Meyenburg H. About the liver cyst. Beitr Pathol Anat 1918;64:477-535.

2. Redston MS, Wanless IR. The hepatic von Meyenburg complex: Prevalence and association with hepatic and renal cysts among 2843 autopsies [corrected]. Mod Pathol 1996;9:233-7.

3. Xu AM, Xian ZH, Zhang $\mathrm{SH}$, Chen XF. Intrahepatic cholangiocarcinoma arising in multiple bile duct hamartomas: Report of two cases and review of the literature. Eur J Gastroenterol Hepatol 2009;21:580-4.

4. Tohmé-Noun C, Cazals D, Noun R, Menassa L, Valla D, Vilgrain V, et al. Multiple biliary hamartomas: Magnetic resonance features with histopathologic correlation. Eur Radiol 2008;18:493-9.

5. Desmet VJ. Congenital diseases of intrahepatic bile ducts: Variations on the theme "ductal plate malformation". Hepatology 1992;16:1069-83.

6. Karhunen PJ. Adult polycystic liver disease and biliary microhamartomas (von meyenburg's complexes). Acta Pathol Microbiol Immunol Scand A 1986;94:397-400.

7. Fritz S, Hackert T, Blaker H, Hartwig W, Schneider L, Buchler MW, et al. Multiple von meyenburg complexes mimicking diffuse liver metastases from esophageal squamous cell carcinoma. World J Gastroenterol 2006;12:4250-2.

8. Vitule LF, Siniuomato FM, de Melo ML, Yoshitake R. Von Meyenburg complex: Case report and literature review. Radiol Bras 2010;43:408-10.

9. Sinakos E, Papalavrentios L, Chourmouzi D, Dimopoulou D, Drevelegas A, Akriviadis E. The clinical presentation of von Meyenburg complexes. Hippokratia 2011;15:170-3.

10. Moorthy K, Mihssin N, Houghton PW. The management of simple hepatic cysts: Sclerotherapy or laparoscopic fenestration. Ann R Coll Surg Engl 2001;83:409-14. 